(IL)-18 as key player in the pathogenesis of $\mathrm{AD}$ and the switch between its two phases.

Objective This study is designed to evaluate serum IL-18 among other T helper (Th) cytokines IL-4, IL-10, IL-12, interferon- $\gamma$ (IFN- $\gamma$ ), tumour necrosis factor $-\alpha(\mathrm{TNF}-\alpha)$ and immunoglobulin $\mathrm{E}$ (Ig E), in addition to vitamins $\mathrm{E}$ and $\mathrm{C}$ in children and adolescents with acute and chronic AD.

Materials and subjects Sixty $\mathrm{AD}$ patients were classified into two main groups; children (acute) and adolescents (chronic) AD of thirty each. In addition, two corresponding healthy normal control groups of thirty each were considered. Serum IL-4, IL10, IL-12, IL-18, IFN- $\gamma$ and IgE were estimated by ELISA.

Results IL-12, IL-18 and IFN- $\gamma$ levels were 2-4 folds more in chronic AD compared to normal subjects. While, IL-18 showed significant higher mean value in chronic than acute $\mathrm{AD}$ patients. Although, TNF $-\alpha$ showed, significant increase one fold and half in acute than chronic AD. Moreover, vitamins $\mathrm{C}$ and $\mathrm{E}$ showed significant decrease in both cases with severe reduction in chronic than acute $\mathrm{AD}$ patients.

Conclusion ILs, IFN- $\gamma$, TNF- $\alpha$ and serum IgE have a pivotal role in AD. IL-18 measurement is a valuable tool for assessment of the difference in age related - disease severity. Intensive reduction in both vitamins $\mathrm{C}$ and $\mathrm{E}$ in chronic $\mathrm{AD}$ patients than acute one.

\section{0-191 EUROPEAN AND INTERNATIONAL INITIATIVES ADDRESSING RARE DISEASES AND CHRONIC AND DISABLING HEALTH CONDITIONS IN CHILDREN: EAP WORKING PARTIES RESEARCH ENGAGEMENTS}

${ }^{1} \mathrm{~F}$ Crawley, ${ }^{2} \mathrm{~J}$ Dodge, ${ }^{3} \mathrm{D}$ Neubauer, ${ }^{4} \mathrm{~L}$ Siderius. ${ }^{1}$ Good Clinical Practice Alliance - Europe, EAP Ethics Working Party, Brussels, Belgium; ${ }^{2}$ University of Swansea, EAP Rare Disease WG, Swansea, UK; ${ }^{3}$ University Children's Hospital Ljubljana, EAP Ethics Working Party, Ljubljana, Slovenia; ${ }^{4}$ Youth Health Care, Icare, Kampen, Netherlands

\subsection{6/archdischild-2014-307384.259}

Background and aims In response to a WHO discussion paper, in December 2013 the European Academy of Paediatrics Working Parties on Ethics and Rare Diseases created a position paper on the early identification, diagnostic confirmation, and longitudinal management of disease in early childhood. The presentation examines the EAP's research engagement in developing infrastructure in primary and specialist care as well as at national and European levels.

Methods The EU Rare Disease programmes and actions, have encouraged the EAP to engage in research on the pooling and structuring of data on child health that can improve global chronic disease prevention and management in paediatric practice. The EAP supports the development of a repository of existing rare disease guidelines. Rare diseases are usually chronic, and in $75 \%$ affect children and/or present in childhood. An EU model will be developed that includes both preventive child health care and rare disease management. For cross-border collaboration is needed to compile patient registries, the development of a shared platform for European patients within the framework of the developing EU eHealth policy is essential: as part of an Open Access Paediatric Healthcare Resource as a child health reference for rare, chronic, and/or disabling diseases.

Results An overview of the current European and international frameworks for rare, chronic, and/or disabling diseases within eHealth is presented.
Conclusions Improved access to knowledge about early diagnosis and disease management for primary and specialist paediatric health care professionals, can bring the EAP experience and expertise to bear on current European and international research.

\section{0-192 CHILDREN'S RIGHTS IN PRIMARY PAEDIATRIC CARE: EUROPEAN STUDY}

${ }^{1} \mathrm{~L}$ Martin-Alvarez, ${ }^{2} \mathrm{P}$ Altorjai, ${ }^{3} \mathrm{Z}$ Kovacs, ${ }^{4} \mathrm{M}$ Katz. ${ }^{1}$ AEPap (Asociación Española Pediatría Atención Primaria), ISSOP (International Society for Social Paediatrics and Child Health), Madrid, Spain; ${ }^{2}$ Association of Hungarian Primary Care Paediatricians, ECPCP (European Confederation of Primary Care Paediatricians), Budapest, Hungary; ${ }^{3}$ Association of Hungarian Primary Care Paediatricians, ISSOP (International Society for Social Paediatrics and Child Health), Budapest, Hungary; ${ }^{4}$ IAPA (Israel Ambulatory Pediatric Association), ISSOP (International Society for Social Paediatrics and Child Health), Tel-Aviv, Israel

\subsection{6/archdischild-2014-307384.260}

Background and aims UN Convention on the Rights of the Child (UNCRC) is an essential part of child health promoting policies. Several studies were carried out on the implementation of UNCRC in secondary and tertiary health care levels but not in primary paediatric care (PPC) settings. PPC model heterogeneity in Europe is related to socioeconomic/demographic factors, paediatric education/training and child health care policies. PPC is either provided by paediatricians or family doctors/GPs.

The study aim was to assess under a social paediatrics perspective UNCRC knowledge/implementation in European PPC settings.

Methods As to profile UNCRC in PPC, a questionnaire (Q1) was designed including 23 specific questions regarding rights of protection, provision and participation. The questionnaire was launched as a "monkey survey" to individual paediatricians practicing in PPC settings through the Council of PPC European national societies participating in the study. Specific country data (Excel table) and total merge data were analysed using SPSS tool.

Results 1342 responses received from 10 participating European PPC societies:

-Not enough knowledge: 52\%-71\%

-Implementation:Partly implemented 30\%-67\%, fully implemented 33-66\%

-Equal access to health care: Provided 84\%-99,5\%

-Right to information: Available 90\%.

Conclusions The knowledge/implementation of UNCRC in PPC varies significantly among European countries. Deep gaps on UNCRC knowledge were found. Equal access to health care is provided in urban areas. UNCRC should be included in paediatric education as well as addressed in PPC planning policies. Further research on UNCRC in various European PPC models/ health care providers is needed (Study Phase 2).

\section{0-193 A DECADE OF CHANGE IN THE PRIMARY CARE EXPERIENCES OF CHILDREN IN THE US WILL REFORM ALIGN THE US MORE CLOSELY WITH EUROPE?}

${ }^{1} \mathrm{~S}$ Gregory, ${ }^{2} \mathrm{~A}$ Kim. ${ }^{1}$ Family Medicine and Preventive Medicine, Keck School of Medicine of University of Southern California, Alhambra, USA; ${ }^{2}$ Preventive Medicine, Keck School of Medicine of University of Southern California, Alhambra, USA

10.1136/archdischild-2014-307384.261 